\title{
IMPACT OF ANODE LAYER THRUSTER PLUMES ON SATELLITE COMMUNICATIONS
}

\author{
Frank S. Gulczinski III $^{*}$ and Alec D. Gallimore ${ }^{\dagger}$ \\ Plasmadynamics and Electric Propulsion Laboratory \\ Department of Aerospace Engineering \\ Douglas O. Carlson ${ }^{\ddagger}$ and Brian E. Gilchrist ${ }^{\S}$ \\ Radiation Laboratory \\ Department of Electrical Engineering and Computer Science \\ The University of Michigan \\ College of Engineering \\ Ann Arbor, Ml 48109
}

\begin{abstract}
Microwave interferometry was used to investigate the impact of the plume of a D-55 anode layer thruster on satellite communications. A $17 \mathrm{GHz}$ microwave signal was transmitted through the plume in order to measure phase shift and signal attenuation at various axial positions and discharge voltages. At $0.25 \mathrm{~m}$ from the thruster exit plane, a centerline phase shift of $37^{\circ}$ was measured with a half-angle at full width half maximum of $22^{\circ}$ for the nominal $300 \mathrm{~V}$ discharge. At $1.00 \mathrm{~m}$, the phase shift had decreased to $20^{\circ}$ and the half-angle to $13.5^{\circ}$. Signal attenuation measurements showed attenuations of $-1.0 \mathrm{~dB}$ to $-1.4 \mathrm{~dB}$ near centerline, but in a double peaked structure that appeared to reflect the annular nature of the plume. Increasing the discharge voltage had no measurable effect on either the phase shift or signal attenuation. Electron number density distributions were calculated by Abel inverting the signal phase shift. For the $300 \mathrm{~V}$ discharge, the centerline number density decreased from $1.0^{*} 10^{11} \mathrm{~cm}^{-3}$ at $0.25 \mathrm{~m}$ to $2.1^{*} 10^{10} \mathrm{~cm}^{-3}$ at $1.00 \mathrm{~m}$. Analysis of the distributions indicates that electrons are not focused by increasing discharge voltage.
\end{abstract}

\section{Introduction}

The anode layer thruster is a Russian developed Halleffect thruster that is being tested and considered for use on western satellites for missions including stationkeeping, repositioning, and orbit transfer. It is very attractive for these roles because it is capable of operating over a wide range of specific impulses, which allows one thruster to perform several missions over the lifetime of the satellite. However, there exists the possibility that signals transmitted to and from the satellite will pass through the thruster's exhaust plume. Due to the plasma density and plasma frequency of the plume, the signal may be phase shifted or attenuated resulting in communications degradation. This study is part of the extension of previous microwave interferometry work at the University of Michigan on

\footnotetext{
- Graduate Student, Aerospace Engineering, Student Member AIAA

${ }^{\dagger}$ Assistant Professor, Aerospace Engineering and Applied Physics, Senior Member AIAA

: Graduate Student Research Assistant, Electrical Engineering and Computer Science

${ }^{\S}$ Associate Professor, Electrical Engineering and Computer Science and Atmospheric, Oceanic and Space Sciences, Member AIAA.
}

Copyright $(\mathcal{O} 1997$ by Frank S. Gulczinski III. $\operatorname{arcjets}^{1}$ and stationary plasma thrusters ${ }^{2}$ to the anode layer thruster.

In addition to determining phase shift and signal attenuation at several axial locations in the near and far field, a range of thruster discharge voltages will be investigated. Experiments using cylindrical and planar Langmuir probes to investigate the ion current density in the plume of a D-55 anode layer thruster at the Central Research Institute of Machine Building (TsNIIMASH) in Kaliningrad, Russia indicated that increasing the thruster's discharge voltage is the most effective method for focusing the ionic components of the plume. ${ }^{3}$ Similar results were found by Manzella and Sankovic. ${ }^{4}$ This study will attempt to determine if the same results occur with the electron-driven RF signal phase shift and attenuation. In order to confirm that ionic plume focusing is observable in the 
University of Michigan's vacuum chamber, radial Faraday probe measurement sweeps were taken at two downstream locations perpendicular to the thruster exit plane and several thruster discharge voltages. The resulting ion current density measurements are presented in Appendix A.

Based on the observed phase shift, Abel inversion can be used to determine the electron number density in the plume from the relationship:

$$
n(r)=-\frac{\lambda n_{c}}{\pi^{2}} \int_{r}^{r}\left(\frac{\partial \phi / \partial x}{\sqrt{x^{2}-r^{2}}}\right) d x
$$

Number density distributions for the various operating conditions and axial locations investigated are presented in this report. This data is compared with Langmuir probe measurements in Appendix B.

\section{Experimental Description}

The experimental measurements described here were performed at the Plasmadynamics and Electric Propulsion Laboratory (PEPL) of the University of Michigan in its $6 \mathrm{~m}$ by $9 \mathrm{~m}$ stainless steel vacuum chamber. Primary pumping is provided by six water cooled oil diffusion pumps, each rated at $32000 \mathrm{l} / \mathrm{s}$ on air. These are backed by two $2000 \mathrm{cfm}$ blowers and four $4000 \mathrm{cfm}$ mechanical pumps, giving the facility an overall measured xenon pumping speed of 30000 $1 / \mathrm{s}$. The pressure during testing was $6.2 * 10^{-5}$ Torr (corrected for xenon). A more complete description of the experimental facility can be found in Gallimore, et al. $^{5}$

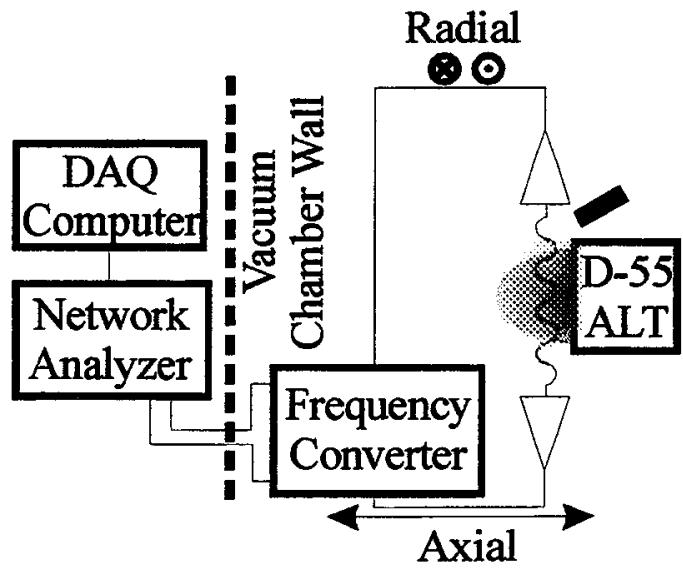

Figure 1: Experimental Setup

The microwave system, shown in Figures 1 and 2 has been designed to work in the $\mathrm{Ku}$ band $(12-18 \mathrm{GHz}){ }^{6}$
Here, measurements were taken using a $17 \mathrm{GHz}$ signal transmitted through the plume of the thruster orthogonally to its axis at a transmitted power of less than $0.1 \mathrm{~mW}$. The measurement system consists of a computer controlled Hewlett Packard 8753B network analyzer connected to a microwave up-down frequency conversion circuit and two lens corrected horn antennas, each with $7^{\circ}$ to $8^{\circ}$ beam widths and a separation of $1.6 \mathrm{~m}$. The network analyzer was calibrated using a Hewlett Packard model 85033D calibration kit with a calibration traceable to NIST. The antenna beams are described by a Gaussian distribution function with a standard deviation of $0.024 \mathrm{~m}^{6}$ The total phase noise of the microwave system is $\pm 0.2^{\circ}$ peak-to-peak, due primarily to a $20 \mathrm{~dB}$ difference between the transmitted and received signals at the network analyzer.

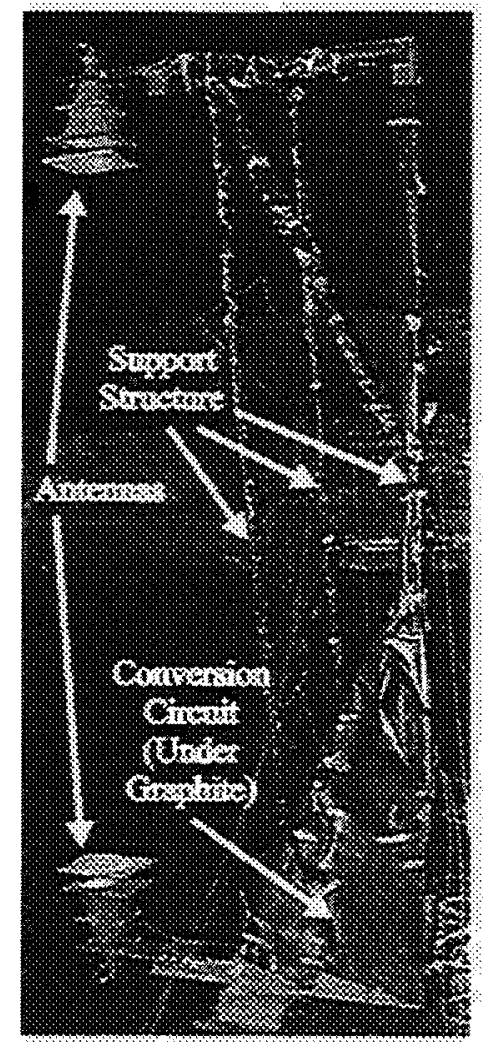

Figure 2: Microwave Interferometer

The microwave interferometer was mounted on PEPL's multi-axis positioning system. This system permits 0.9 $\mathrm{m}$ travel perpendicular to the thruster exit plane (axial) and $1.5 \mathrm{~m}$ travel parallel to the exit plane (radial). The table movement produces an additional vibrational noise proportional to the velocity and acceleration of the table. During these tests, the table was accelerated at $0.01 \mathrm{~m} / \mathrm{s}^{2}$ and traveled at a radial speed of $0.01 \mathrm{~m} / \mathrm{s}$, producing an additional $\pm 1.4^{\circ}$ of noise. The support 
structure was covered with thin graphite sheeting to prevent sputtering.

The thruster used in this experiment, shown in Figure 3 , is a model D-55 anode layer thruster developed by TsNIIMASH which is on loan from the Jet Propulsion Laboratory. The D-55 has nominal discharge operating conditions of $300 \mathrm{~V}$ and $4.5 \mathrm{~A}(1.35 \mathrm{~kW})$ with xenon as its primary propellant. A more complete description of the D-55 can be found in Garner, et al. ${ }^{\text {? }}$

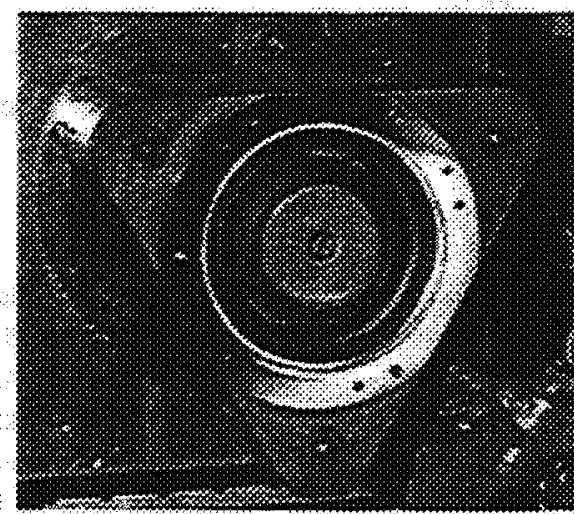

Figure 3: D-55 Anode Layer Thruster

Radial sweeps of the thruster plume were taken at axial distances of $0.25 \mathrm{~m}, 0.50 \mathrm{~m}$, and $1.00 \mathrm{~m}$ from the exit plane, and at discharge voltages ranging from $200 \mathrm{~V}$ to $350 \mathrm{~V}$ in $50 \mathrm{~V}$ increments. Due to the asymmetry of the microwave interferometer mounting structure, radial measurements were taken from $-0.533 \mathrm{~m}$ to $+0.978 \mathrm{~m}$, measured from the thruster centerline.

\section{Experimental Results}

The results for signal phase shift at the three axial locations are given in Figures 4 through 6:

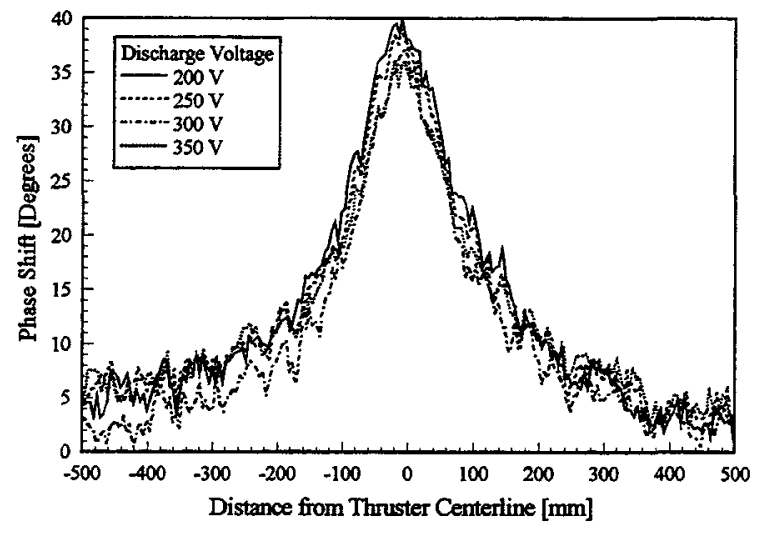

Figure 4: Phase Shift at $0.25 \mathrm{~m}$ Axially

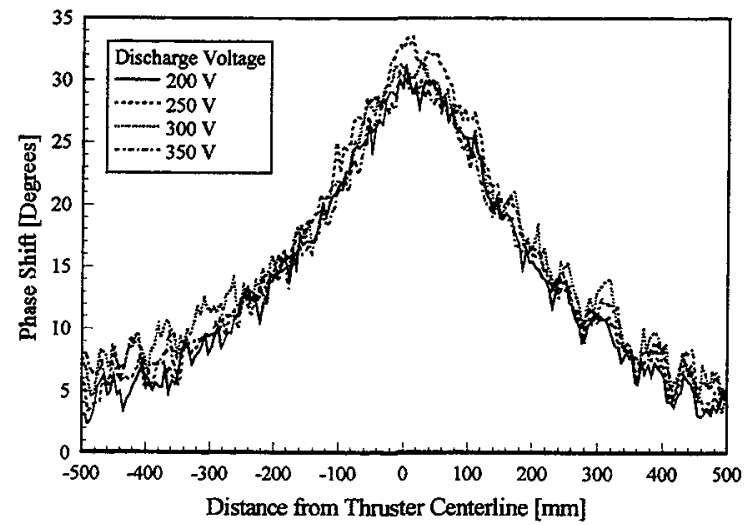

Figure 5: Phase Shift at $0.50 \mathrm{~m}$ Axially

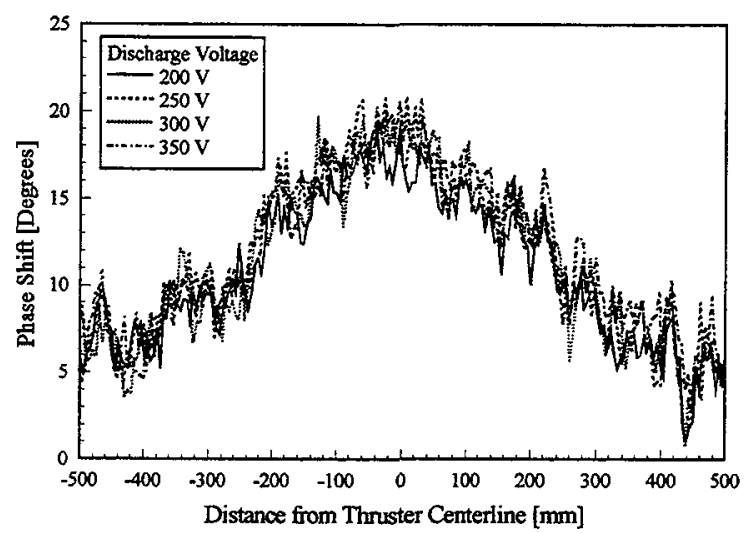

Figure 6: Phase Shift at $1.00 \mathrm{~m}$ Axially

The phase shift at a discharge voltage of $300 \mathrm{~V}$ for all axial locations is given in Figure 7:

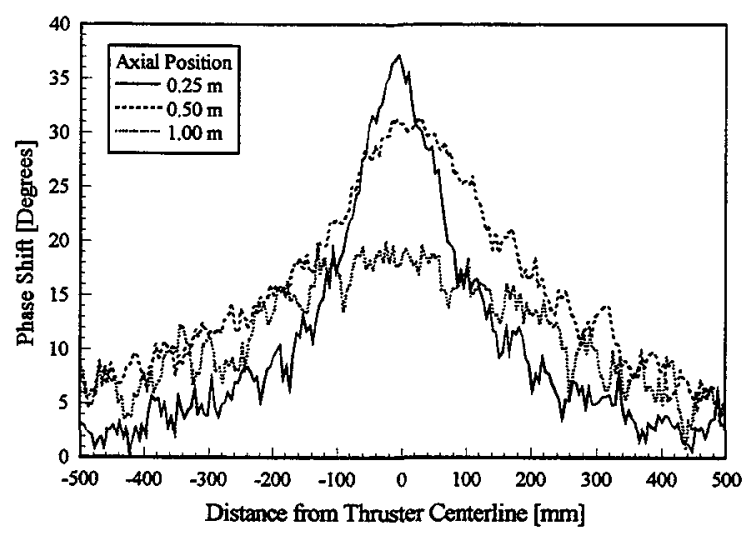

Figure 7: Phase Shift for 300 V Discharge Voltage

The signal attenuation data for the three axial locations is given in Figures 8 through 10: 


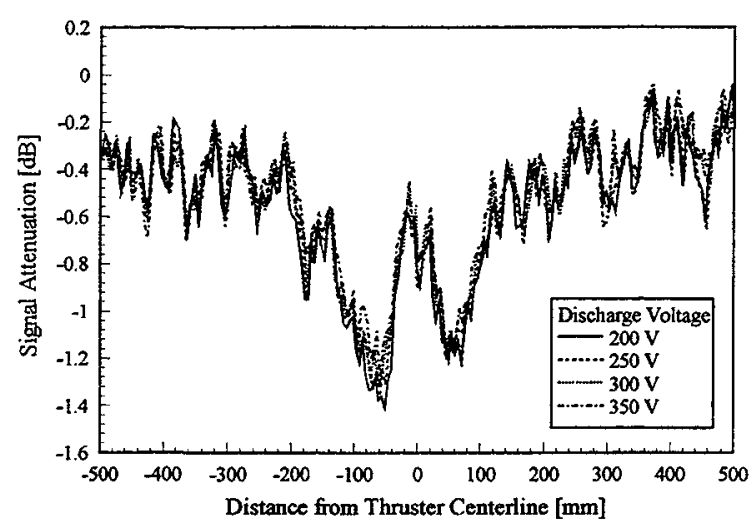

Figure 8: Signal Attenuation at $0.25 \mathrm{~m}$ Axially

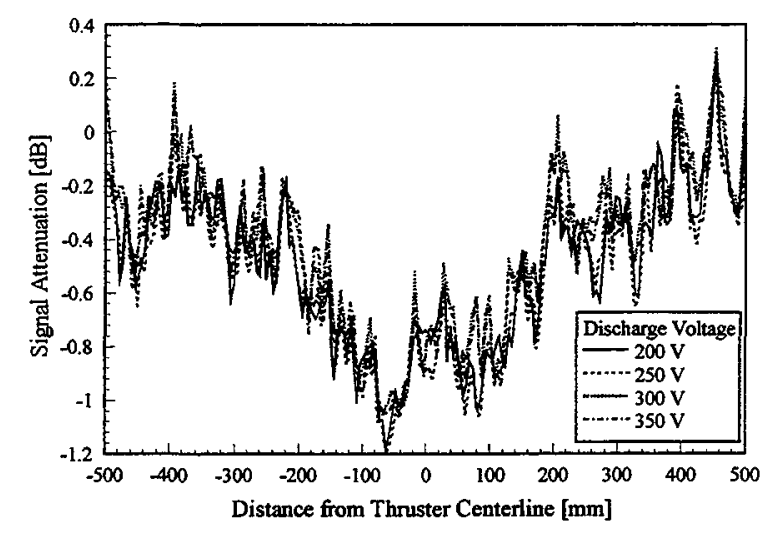

Figure 9: Signal Attenuation at $0.50 \mathrm{~m}$ Axially

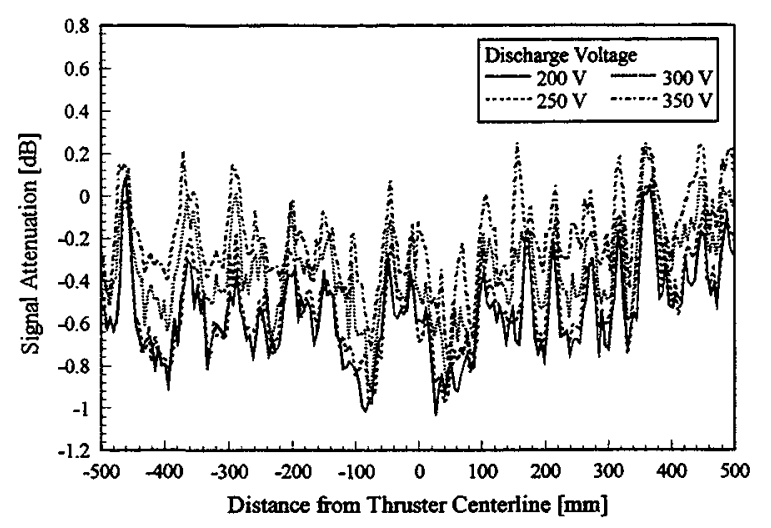

Figure 10: Signal Attenuation at $1.00 \mathrm{~m}$ Axially

A summary of the attenuation at a discharge voltage of $300 \mathrm{~V}$ for all axial locations is given in Figure 11:

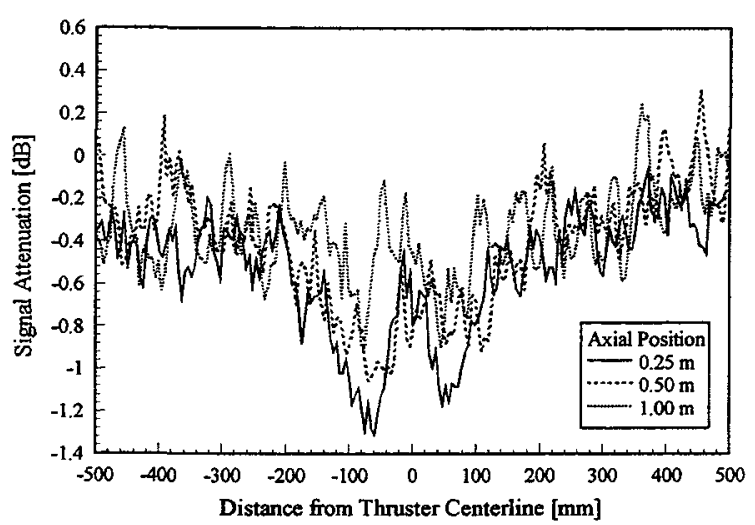

Figure 11: Signal Attenuation for $300 \mathrm{~V}$ Discharge Voltage

\section{Data Analysis and Discussion}

The results shown in Figures 4 through 6 indicate a well defined region of signal phase shift within the plume of the anode layer thruster that must be accounted for by satellite designers when positioning thrusters and antennas. This is especially true if the satellite is intended to send or receive signals that are encoded such that they are phase sensitive. For all of the axial cases, the difference between the various voltage cases was within the total phase noise of $\pm 1.6^{\circ}$. Therefore, the raw phase data alone does not indicate whether increasing the thruster discharge voltage focuses the plume with respect to communications signals.

Examining the evolution of the phase shift region moving axially away from the thruster in Figure 7 we note that, for the $300 \mathrm{~V}$ case, the shift at thruster centerline decreases from $37^{\circ}$ at $0.25 \mathrm{~m}$ to $20^{\circ}$ at 1.00 m. Using the full width at half maximum as a reference point, the phase region increases in width as the plume diffuses outward. However, converting to cylindrical coordinates we note that the half-angle measured from the thruster centerline to the edge of the phase shift region decreases from $22^{\circ}$ at $0.25 \mathrm{~m}$ to $13.5^{\circ}$ at $1.00 \mathrm{~m}$.

Examining the signal attenuation data in Figures 8 through 10, we note that the ratio of attenuation to noise is less than the ratio of phase shift to noise since the plume has a much larger effect on the signal's phase than on its magnitude. Also note that there is very little difference between the various voltage cases, especially considering the level of noise involved.

As seen in Figure 8, at $0.25 \mathrm{~m}$ from the thruster exit plane, there are two strong peaks in the signal 
attenuation of $-1.2 \mathrm{~dB}$ and $-1.4 \mathrm{~dB}$ at $\pm 0.06 \mathrm{~m}$ from the thruster centerline. There is a gap between these two peaks, the magnitude of which is larger than the typical noise observed in the attenuation measurements (which can be seen at radial distances greater than 0.2 $\mathrm{m})$. This leads to the conclusion that what is being seen is the effect of the annular structure of the anode layer thruster plume on RF signals. It is believed that the difference between the two peaks is due to the noise in the system. It appears that this structure is also evident at $0.5 \mathrm{~m}$ (Figure 9) though the peaks are weaker $(-1.0 \mathrm{~dB}$ and $-1.2 \mathrm{~dB})$ and wider, and thus appear to be converging. It could conceivably be argued that this structure can also be seen at $1.00 \mathrm{~m}$ in Figure 10, but given the low signal to noise ratio at this point it is not clear that this is the case. Overall, as shown in Figure 11 for the $300 \mathrm{~V}$ discharge case, there is a signal attenuation of approximately $-1.0 \mathrm{~dB}$ to -1.4 $\mathrm{dB}$ near the thruster centerline, which would prove especially detrimental to satellites that have low transmission power levels.

Electron number density distributions in the plume were determined by an Abel inversion technique. First, a double transformation (Fourier, then Hankel) was performed on Equation 1 to avoid computational issues associated with noise introduced by the derivative of the raw data and the singularity at the integral end point. Next, filters were used to remove data noise and the antenna pattern from $\phi(x)^{6}$ before the Abel inversion technique was applied to give the number density profile. The resulting profiles are shown in Figures 12 through 14 for the three axial locations. The bumps in number density at large radial distances are the result of the filtering and deconvolution process.

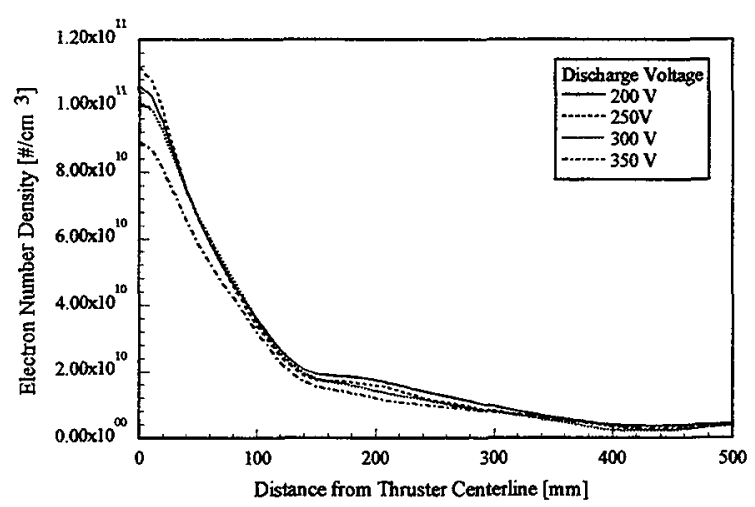

Figure 12: Electron Density at $0.25 \mathrm{~m}$ Axially

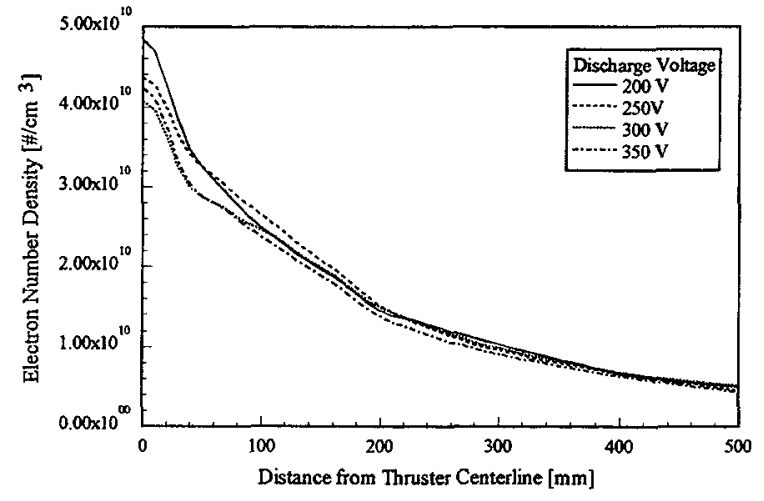

Figure 13: Electron Number Density at $0.50 \mathrm{~m}$ Axially

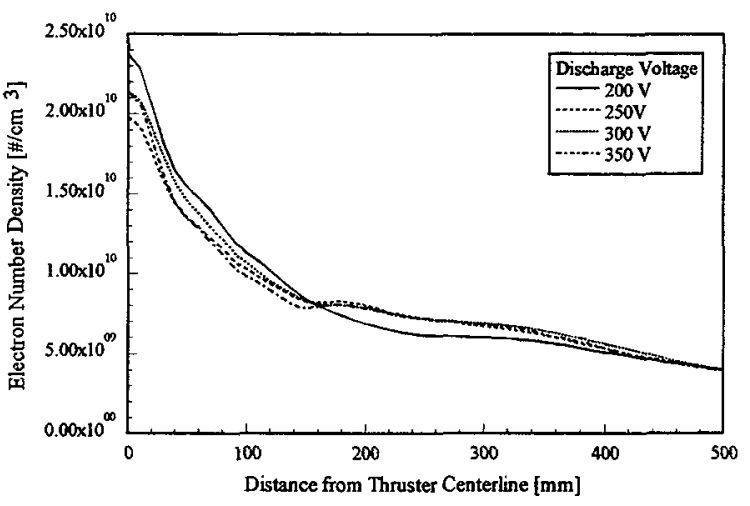

Figure 14: Electron Number Density at $1.00 \mathrm{~m}$ Axially

Figure 15 contains a summary of the results for a discharge voltage of $300 \mathrm{~V}$.

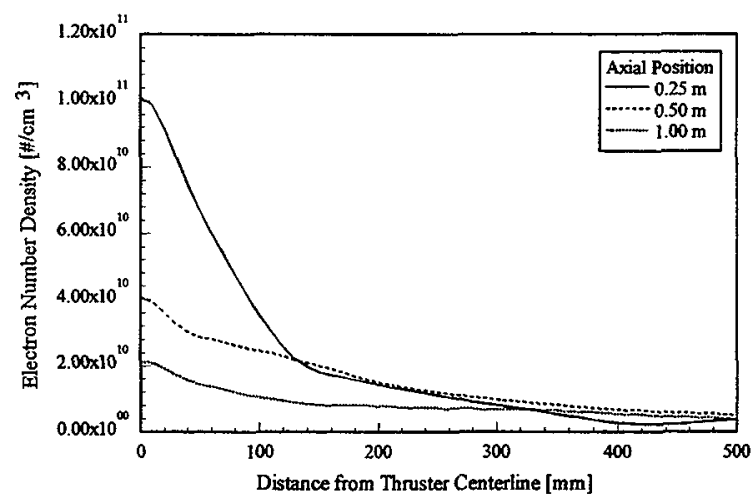

Figure 15: Electron Number Density for $300 \mathrm{~V}$ Discharge Voltage

In examining these number density profiles, one might expect that there would be structure seen similar to the ion profiles shown by Borisov ${ }^{3}$, Manzella and Sankovic ${ }^{4}$, and in Appendix A since, in order to neutralize the exhaust beam of the anode layer thruster, the electrons must follow the ions. However, since the electrons are much more mobile than the ions, one 
might conclude that any such structure would be less defined.

After analyzing the data in Figures 12 - 14, it appears that this theory is not valid. Ion focusing is seen as an increase in the peak value of the ion current density and a narrowing of the profile (Figures A1 and A2) as discharge voltage is increased. Though there are spreads in the electron number density profiles, they do not follow the trends seen in ion focusing and appear, in fact, to be random. Previous interferometry work with this system estimated an uncertainty of $\pm 17 \%$ and a repeatability of $\pm 10 \%{ }^{2}$ The measurements in this study fall within these ranges. It is theorized that the increased mobility and subsequent diffusion of the electrons results in the formation of a neutralizing cloud, the density of which is independent of discharge voltage, through which the ions pass as they travel away from the thruster. This allows quasineutrality to be maintained even though the electrons do not conform to the ion distribution patterns.

Examining the evolution of number density with axial location in Figure 15 we see, as expected, that due to diffusion the magnitude of the peak density decreases and the width of the profile increases as the distance from the exit plane increases.

\section{Summary}

Microwave interferometry facilitates the measurement of phase shift and attenuation allowing satellite designers to determine proper positioning of antennas and thrusters so as to minimize communications degradation. This is especially critical if there is low transmission power available on the satellite or if the signal is encoded in such a manner that it is sensitive to phase shift. Thruster discharge voltage appears to make little or no difference in the phase shift and attenuation of a communications signal passing through the plume in the $\mathrm{Ku}$ band. The electron number density profiles do not indicate that the electrons follow the ions and thus are not focused by an increase in discharge voltage. For all parameters examined, increasing the distance from the thruster exit plane broadened their profile and decreased their peak values.

\section{Acknowledgements}

The research contained herein was sponsored by the Air Force Office of Scientific Research under Dr. Mitat Birkan; this support is gratefully acknowledged. The authors wish to thank Dr. Shawn Ohler of MIT
Lincoln Laboratories, who designed and built the microwave interferometry system used here while at the University of Michigan. They also wish to thank their fellow researchers at PEPL and the Radiation Lab for their invaluable assistance in performing these experiments, especially Mr. Sang-Wook Kim for assistance with the Langmuir probe measurements and Mr. Matthew Domonkos for the operation of the D-55 and assistance with the Faraday probe measurements. The authors would like to thank the Jet Propulsion Laboratory for the loan of the D-55, and Sasha Semenkin and Sergei Tverdokhlebov of TsNIIMASH for their assistance in the initial and continued operation of the D-55. Mr. Frank Gulczinski is supported by the United States Air Force Palace Knight Program.

\section{References}

1 Ohler, S.G., Gilchrist, B.E., and Gallimore, A.D., "Non-intrusive Plasma Diagnostics for Electric Propulsion Research," AIAA 94-3297, June 1994.

2 Ohler, S.G., Gilchrist, B.E., and Gallimore, A.D., "Microwave Plume Measurements of an SPT-100 Using Xenon and a Laboratory Model SPT Using Krypton," AIAA 95-2931, July 1995.

${ }^{3}$ Borisov, B.S., et al., "Experimental Study of Exhaust Beam of Anode Layer Thruster," IEPC 95-051, September 1995.

${ }^{4}$ Manzella, D.H. and Sankovic, J.M., "Hall Thruster Ion Beam Characterization," AIAA 95-2927, July 1995.

${ }^{5}$ Gallimore, A.D., et al., "Near and Far-Field Plume Studies of a $1 \mathrm{~kW}$ Arcjet," Journal of Propulsion and Power, January-February 1996.

${ }^{6}$ Ohler, S.G., Gilchrist, B.E., and Gallimore, A.D., 'Non-intrusive electron number density measurements in the plume of a $1 \mathrm{~kW}$ arcjet using a modern microwave interferometer," IEEE Transactions on Plasma Science, June 1995.

7 Garner, C.E., et al., "Experimental Evaluation of Russian Anode Layer Thrusters," AIAA 94-3010, June 1994. 


\section{Appendix A}

\section{Far Field Ion Current Density for the D-55 Anode Layer Thruster}

In order to investigate the detectability of plume focusing in the PEPL vacuum facility, far field ion current density measurements were taken in the plume of the D-55 anode layer thruster using a Faraday probe. The probe and techniques were the same as those used by Marrese, et al. in their investigation of the D-100 anode layer thruster. ${ }^{\mathrm{A} 1}$ The voltage read by the Faraday probe is related to the ion current density by the simple formula:

$$
\mathrm{J}_{\text {ion }}=\frac{\mathrm{V}_{\text {probe }}}{\mathrm{A}_{\text {probe }} \mathrm{R}_{\text {shunt }}} .
$$

The probe area was $4.34 * 10^{-4} \mathrm{~m}^{2}$ and the shunt resistances were $9.94 \Omega$ and $20 \Omega$ for the $0.25 \mathrm{~m}$ and $0.50 \mathrm{~m}$ cases, respectively.

The ion current density measurements are presented in the following figures. For the $0.25 \mathrm{~m}$ case, measurements were not taken at radial distances greater than $+0.15 \mathrm{~m}$ at $300 \mathrm{~V}$ or at any position at 350 $\mathrm{V}$ due to probe failure.

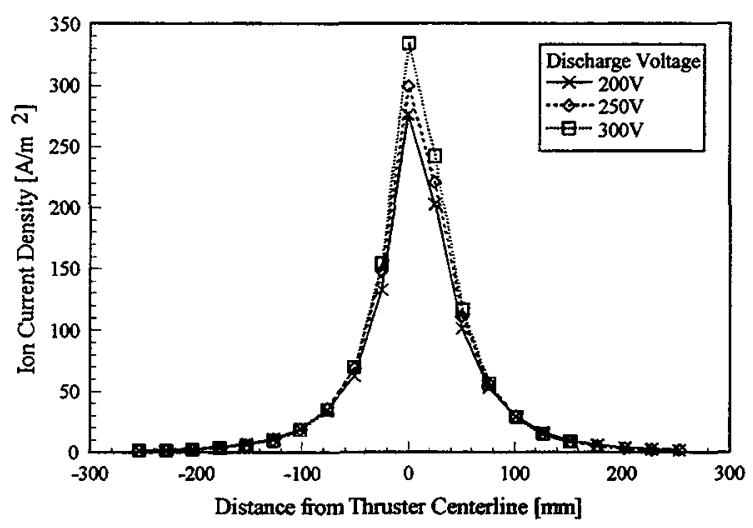

Figure A1: Ion Current Density at $0.25 \mathrm{~m}$ Axially

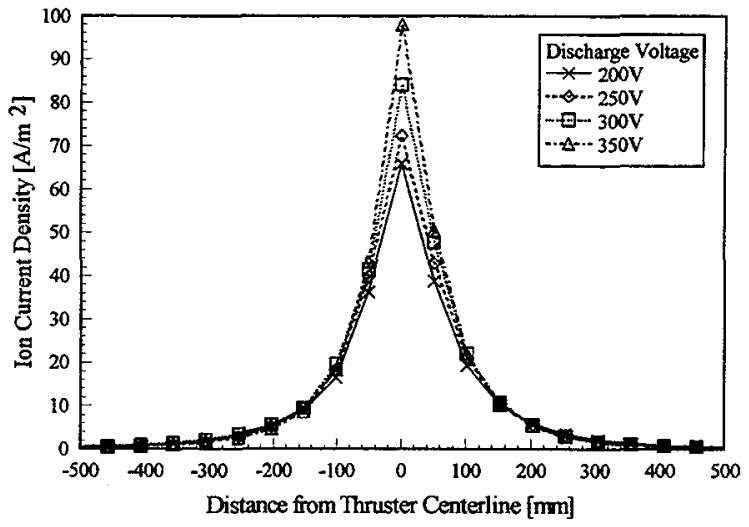

Figure A2: Ion Current Density at $0.50 \mathrm{~m}$ Axially

Comparing the results of Figure A2 to those of Manzella and Sankovic ${ }^{\mathrm{A} 2}$ (taken on a constant radius arc $0.6 \mathrm{~m}$ from the thruster exit) we find that the PEPL measurements are slightly higher but that they follow the same trends in profile shapes. Given the numerous differences between the two tests (thruster, probe, facility pressure, etc.) we feel that this adequately demonstrates the detectability of thruster focusing in the PEPL vacuum facility.

The enclosed currents from Figures $\mathrm{A} 1$ and $\mathrm{A} 2$ are given in Table A1:

\begin{tabular}{r|cc} 
& \multicolumn{2}{|c}{ Axial Distance } \\
Discharge Voltage & $0.25 \mathrm{~m}$ & $0.50 \mathrm{~m}$ \\
\hline $200 \mathrm{~V}$ & $2.44 \mathrm{~A}$ & $3.01 \mathrm{~A}$ \\
$250 \mathrm{~V}$ & $2.48 \mathrm{~A}$ & $3.06 \mathrm{~A}$ \\
$300 \mathrm{~V}$ & $2.47 \mathrm{~A}$ & $3.13 \mathrm{~A}$ \\
$350 \mathrm{~V}$ & $\mathrm{X}$ & $3.16 \mathrm{~A}$
\end{tabular}

Table A1: Enclosed Current for Faraday Probe Measurements

\section{References}

Al Maresse, C.M., et al, "D-100 Performance and Plume Characterization on Krypton," AIAA 96-2969, July 1996.

A2 Manzella, D.H. and Sankovic, J.M., "Hall Thruster Ion Beam Characterization," AIAA 95-2927, July 1995. 


\section{Appendix B}

\section{Comparison of Microwave Interferometry and Langmuir Probe Electron Density Measurements}

In order to compare the microwave interferometry electron density measurements shown in Figures 12 and 13 to probe measurements, a cylindrical Langmuir probe was swept to various locations within the plume. The probe was a rhenium coated design, previously used at PEPL to examine the far field of a $1.35 \mathrm{~kW}$ arcjet. $^{\text {B1 }}$ The probe used a $9.94 \Omega$ shunt and was driven by a function generator and bipolar power supply, a method previously used by Kim, et al. ${ }^{\mathrm{B} 2}$ The probe had a radius of $0.0021 \mathrm{~m}$ and was $0.051 \mathrm{~m}$ long, giving a collection surface area of $6.87 * 10^{-4} \mathrm{~m}^{2}$.

The resultant Langmuir probe traces were analyzed using a thin sheath, ion saturation model. This model was justified because the probe radius was much less than the electron mean free path $\left(3^{*} 10^{3} \mathrm{~m}\right)$ and much greater than the Debye length $\left(4^{*} 10^{-5} \mathrm{~m}\right)$. Measurements were taken $0.25 \mathrm{~m}$ and $0.50 \mathrm{~m}$ axially from the thruster. No attempt was made to align the probe with the flow vector, since only order of magnitude measurements were desired.

The electron temperature profiles are given in Figure B1.

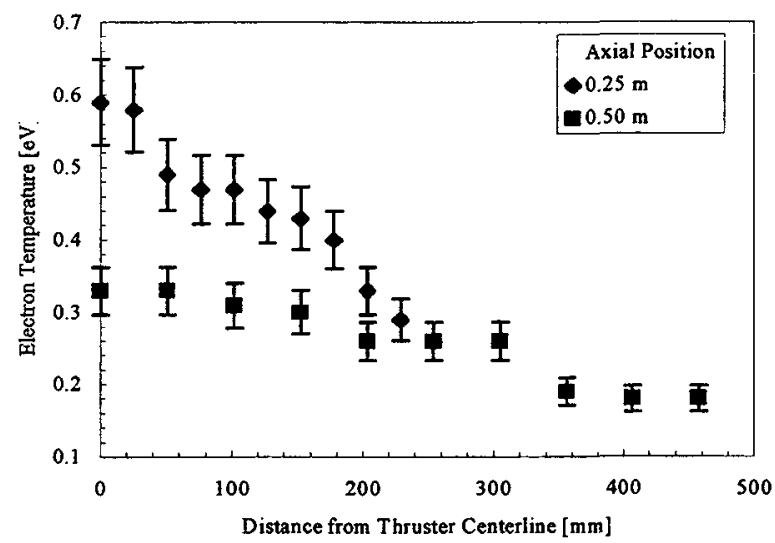

Figure B1: Electron Temperature for $300 \mathrm{~V}$ Discharge Voltage

The electron number density profiles, along with the corresponding microwave interferometer results, are given in the following figures:

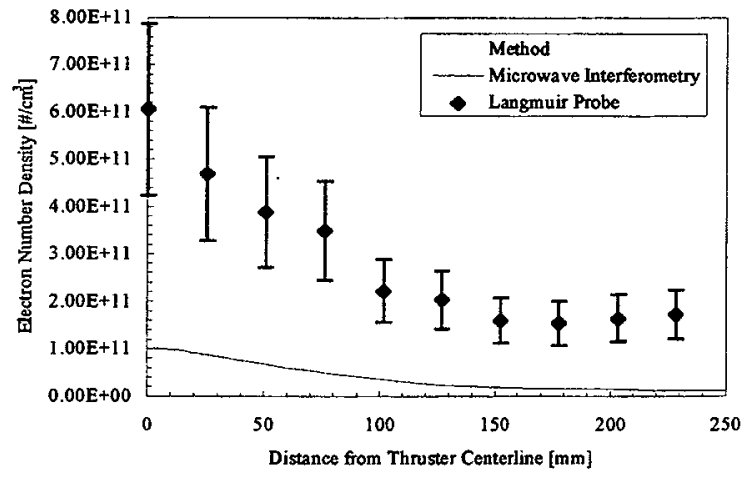

Figure B2: Comparison of Electron Density Results at $0.25 \mathrm{~m}$ Axially

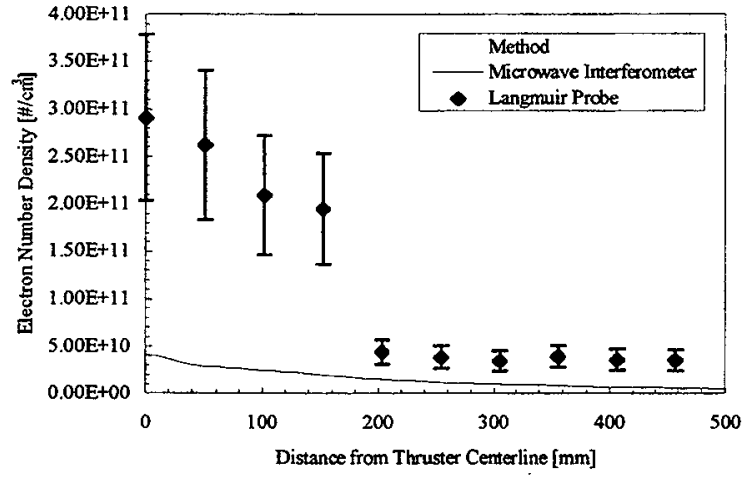

Figure B3: Comparison of Electron Density Results at $0.50 \mathrm{~m}$ Axially

The Langmuir probe measurements indicate consistently higher electron number densities than the microwave interferometer. They do, however, agree within the order of magnitude that was sought in this experiment.

\section{Referencès}

${ }^{\text {B1 }}$ Gallimore, A.D., et al., "Near and Far-Field Plume Studies of a $1 \mathrm{~kW}$ Arcjet," Journal of Propulsion and Power, January-February 1996.

${ }^{\text {B2 }}$ Kim, S.-W., Foster, J.E., Gallimore, A.D., "VeryNear-Field Plume Study of a $1.35 \mathrm{~kW}$ SPT-100," AIAA 96-2972, July 1996. 